\title{
Expression of HGF/c-Met Is Dynamically Regulated in the Dorsal Root Ganglions and Spinal Cord of Adult Rats following Sciatic Nerve Ligation
}

\author{
Lin-Feng Zheng ${ }^{a}, b$ Rui Wang ${ }^{c}$ Qing-Ping Yu ${ }^{b}$ Han Wang ${ }^{a}$ Xi-Nan $\mathrm{Yi}^{c}$ \\ Qi-Ben Wang ${ }^{b}$ Jian-Wei Zhang ${ }^{b}$ Gui-Xiang Zhang ${ }^{a}$ Yuan-Zhong $X^{b}{ }^{b}, d$ \\ aDepartment of Radiology, Shanghai Jiaotong University Affiliated First People's Hospital, Shanghai Jiaotong \\ University School of Medicine, Shanghai, b Department of Anatomy and Neurobiology, Xiangya School of \\ Medicine, Central South University, Changsha, and 'Department of Anatomy, Hainan Medical College, \\ Hainan, China; ${ }^{\mathrm{d} C e n t e r}$ for Obesity and Diabetes, The Brown Foundation Institution of Molecular Medicine, \\ The University of Texas Health Science Center at Houston, Houston, Tex., USA
}

\section{Key Words}

Peripheral nerve injury · Regeneration · Hepatocyte growth factor · c-Met receptor • Neurotrophic effects • Rodents

\begin{abstract}
Hepatocyte growth factor (HGF) and its receptor c-Met play pivotal roles in post-traumatic regeneration of the nervous system. However, following peripheral nerve injury, the role and regulation of the HGF/c-Met system is less clear. Therefore, using a sciatic nerve ligation (SNL) model, spatiotemporal changes in HGF and c-Met expression were detected in the dorsal root ganglions (DRGs) and lumbar spinal cords of adult rats. HGF expression following SNL was found to be significantly decreased in ipsilateral L4-L5 DRGs from day 3 to day 14, with the lowest levels of expression detected on days 5 and 7. In contrast, no significant change in HGF expression was detected in the lumbar spinal cords. c-Met expression in ipsilateral L4-L5 DRGs and within the ipsilateral dorsal horn was found to be significantly up-regulated following SNL, particularly from day 5 to day 14, with peak levels of expression detected on days 7 and 14 . In contrast, c-Met levels following SNL consistently remained stable in the spinal ventral horn. These findings suggest that the
\end{abstract}

HGF/c-Met system is spatiotemporally regulated by a unique pattern of signaling pathways induced by peripheral nerve injury, and these pathways have a role in promoting the survival of injured neurons, especially adult DRG sensory neurons.

Copyright $\odot 2010$ S. Karger AG, Basel

\section{Introduction}

Hepatocyte growth factor (HGF) has been a subject of study since it was first discovered as a muscle-derived neurotrophic factor present in both the central nervous system (CNS) and the peripheral nervous system (PNS) $[1,2]$. Additionally, HGF has been associated with promoting survival of motor, sensory, and parasympathetic neurons [3-6], inducing neurite outgrowth and migration [7], enhancing functional recovery of axonal regeneration $[8,9]$, preventing cell death of ischemia-damaged neurons $[10,11]$, suppressing progression of neurodegenerative diseases [12, 13], and improving learning and memory dysfunction of impaired brains [14]. The ability of HGF to mediate such as wide range of biological functions is based on its interactions with its unique receptor, Met tyrosine kinase receptor (c-Met) [15].

\section{KARGER}

Fax +41613061234 E-Mail karger@karger.ch www.karger.com
Gui-Xiang Zhang, Department of Radiology

Shanghai Jiaotong University Affiliated First People's Hospital

Shanghai Jiaotong University School of Medicine, Shanghai 200080 (China)

Tel. +86 2163240090 4166, Fax +86216324 0825, E-Mail guixiangzhang@ sina.com

${ }^{1}$ Co-corresponding author 
While the role of HGF in the developing and mature CNS has been well studied $[9,16-20]$, there have been fewer studies on the dynamic features of the HGF/c-Met system in PNS-related structures. For example, in naive adult rats, HGF mRNA is primarily expressed by $\sim 25 \%$ of primary sensory neurons in the dorsal root ganglions (DRGs), and is abundantly distributed in laminae IIIVIII of the spinal cord. In contrast, c-Met mRNA has been predominantly detected in the superficial layers of the spinal dorsal horn, in most motoneurons in the spinal ventral horn [21,22], and in Schwann cells in the sciatic nerve of adult rats [21]. In injury-related regions following peripheral nerve injury, mRNA and protein levels of cMet have been shown to be spatiotemporally regulated, whereas levels of mRNA and protein of HGF have been shown to remain stable following axotomy [21, 23-25]. Despite these insights into $\mathrm{HGF} / \mathrm{c}$-Met signaling, the mechanisms specifically involved following peripheral nerve injury have not been completely elucidated.

In the present study, spatiotemporal changes in the expression of HGF and c-Met were investigated in L4-L5 DRGs and the lumbar spinal cord following sciatic nerve ligation (SNL) in adult rats. In a previous study, $85 \%$ of DRG neurons that were positive for HGF mRNA, were also found to be positive for trkA mRNA. trkA is a high affinity receptor for nerve growth factor (NGF) [21], and NGF has been shown to promote the survival of different types of neurons in coordination with HGF [26]. Therefore, protein levels of NGF were also detected within the sciatic nerve following SNL [27]. Our findings indicate that the HGF/c-Met system is spatiotemporally regulated following peripheral nerve injury, and the unique signaling pattern for this system further suggests a role for HGF/c-Met in promoting the survival of adult DRG sensory neurons and spinal motoneurons.

\section{Materials and Methods}

\section{Animals and Surgery}

Adult male Sprague-Dawley rats, weighing 200-250 g, were obtained from the Xiangya Center of Experimental Animals, Changsha, China. All surgical procedures and post-operative animal care were carried out according to protocols approved by the institutional committee for animal care, and also in accordance with the policy of the National Ministry of Health. All efforts were made to minimize the number of animal used and their discomfort following nerve surgery.

Using sodium pentobarbital (i.p., $40 \mathrm{mg} / \mathrm{kg}$ ) to induce deep anesthesia, the right sciatic nerve was exposed and tightly ligated with a 4-0 nylon thread at mid-thigh level. In sham control rats, the right sciatic nerve was exposed but not injured. Following sur- gery, animals were administered antibiotic ointment prophylactically and then returned to their cages to awake without immobilization. Normal controls included rats that did not undergo surgery.

\section{Tissue Processing}

Following ligation surgery, 5 rats from each treatment group were harvested on days $1,3,5,7,14$, and 28 for immunohistochemical analysis. Under deep anesthesia, rats were perfused transcardially with saline followed by freshly prepared $4 \%$ paraformaldehyde in $0.1 \mathrm{M}$ phosphate buffer ( $\mathrm{PB}, \mathrm{pH}$ 7.4). Subsequently, bilateral L4-L5 DRGs and corresponding segments of the lumber spinal cords of injured rats, plus 2 normal rats, were removed and post-fixed in the same fixative for $3 \mathrm{~h}$. Tissues were then transferred to $30 \%$ sucrose in $0.1 \mathrm{M} \mathrm{PB}$ for cryoprotection, embedded in OCT (Tissue Tek; Miles Laboratories, Elkhart, Ind., USA), and stored at $-80^{\circ} \mathrm{C}$. All specimens were sliced coronally using a Shandon cryostat and the $20-\mu \mathrm{m}$ sections obtained were labeled as an adjacent series.

For immunoblotting samples, 5 rats from each timepoint were sacrificed by decapitation and the bilateral L4-L5 DRGs, the L4L5 segments of the lumber spinal cord (the ventral $1 / 2$ part) were rapidly dissected from each. As described previously [27], dissected samples were combined with $5 \mathrm{vol}(\mathrm{w} / \mathrm{v})$ of ice-cold lysis buffer (150 m M NaCl, 1\% Nonidet P40, 0.5\% sodium deoxycholate, $0.1 \%$ SDS, and $1 \mathrm{~mm}$ sodium orthovanadate in $50 \mathrm{mM}$ Tris- $\mathrm{HCl}(\mathrm{pH}$ 7.4)), homogenized using a Dounce homogenizer, and centrifuged $(12,000 \mathrm{~g})$ for $15 \mathrm{~min}$ at $4^{\circ} \mathrm{C}$. After $30 \mathrm{~min}$ on ice, supernatants were collected and immediately stored at $-80^{\circ} \mathrm{C}$ until needed.

\section{Immunohistochemistry}

Two series of free-floating DRG and spinal cord sections were rinsed in PBS containing 0.1\% Triton X-100, then soaked in 3\% $\mathrm{H}_{2} \mathrm{O}_{2}$ in PBS for 20 min to inactive endogenous peroxidase activity. Sections were subsequently blocked in a solution of $5 \%$ bovine serum albumin (BSA)/0.3\% Triton X-100/PBS for $1 \mathrm{~h}$ at room temperature (RT), followed by incubation of the sections with polyclonal primary antibodies raised in rabbit to HGF and c-Met (1:200; Santa Cruz Biotechnology, Santa Cruz, Calif., USA) overnight at $4{ }^{\circ} \mathrm{C}$. For control sections, primary antibody was omitted. After 3 washes in PBS, sections were incubated for $2 \mathrm{~h}$ at RT with biotinylated secondary goat anti-rabbit IgGs (1:200; Vector, Burlingame, Calif., USA) in the same solution used for the primary antibodies. Sections were then reacted with avidin-peroxidase complex (1:100; Vector) for $1 \mathrm{~h}$ and bound antibody was visualized using 3'3-diaminobenzidine as a chromogen. After several rinses in PBS, sections were mounted onto gelatin-coated slides, air-dried, dehydrated, cleared, and coverslips were applied.

Double immunofluorescent staining was performed on DRG sections with c-Met plus mouse anti-5-hydroxytryptamine (5HT; 1:500; Chemicon, Temecula, Calif., USA) or mouse anti-glial fibrillary acidic protein (GFAP; 1:500; Chemicon). For spinal cord sections, c-Met plus goat anti-ChAT (1:500; Chemicon) or goat anti-calcium gene-related peptide (CGRP) (1:1,000; Biogenesis, Poole, UK) were used. Immunoreactivities were visualized using species-specific secondary antibodies raised in donkey that were conjugated to Cy2 or Cy3 (1:100; Jackson ImmunoResearch, Newmarket, UK). 

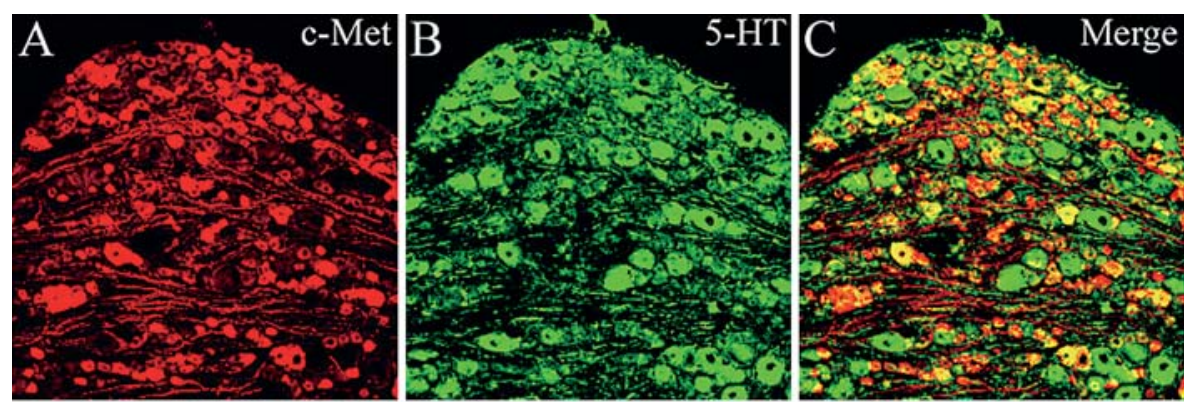

Fig. 1. Immunofluorescent images of cMet expression in L4-L5 DRGs of a control rat. Immunopositive cells were associated with a range of different diameters of primary sensory neurons, however, high levels of c-Met were associated with neurons of small or medium diameter $(\mathbf{A}-\mathbf{C})$. Co-expression of c-Met and GFAP was detected along sensory fibers within DRGs (D-F). Scale bar $=100 \mu \mathrm{m}$ in all images.
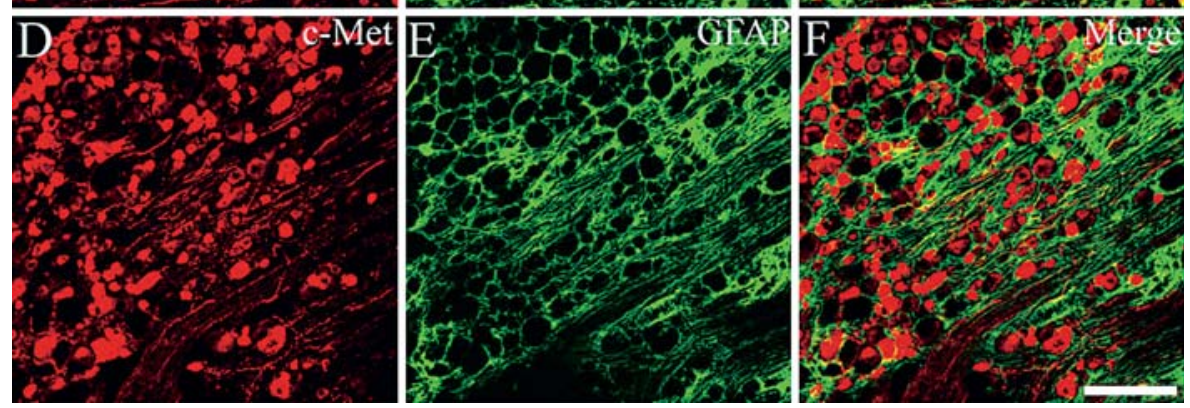

At each timepoint, 6 spinal cord sections were randomly selected from each animal and stained for c-Met. At corresponding rostrocaudal levels, antibody binding was detected using a light microscope (40× magnification) and recorded (Nikon, Tokyo, Japan). Analysis of digitized images was performed using Image Pro Plus 5.0 for Windows, with the target area within the superficial laminae of the lumbar spinal dorsal horn automatically quantified $\left(\mu \mathrm{m}^{2}\right)$.

\section{Immunoblotting}

Total protein lysate $(20 \mu \mathrm{g})$ for each sample was separated electrophoretically in 5\% SDS-polyacrylamide gels and transferred to polyvinylidene fluoride membranes. Membranes were blocked with $5 \% \mathrm{BSA}$ in $0.1 \mathrm{M}$ Tris-buffered saline containing $0.1 \%$ Tween-20 (TBS-T) for $1 \mathrm{~h}$ at RT, then incubated overnight at $4^{\circ} \mathrm{C}$ with polyclonal rabbit anti-c-Met $(1: 500)$ in TBS-T containing $1 \%$ BSA. Membranes were washed thoroughly with TBS-T and then were incubated for $1 \mathrm{~h}$ at RT with horseradish peroxidase-conjugated goat anti-rabbit IgGs (1:1,000; Dako, Glostrup, Denmark). Levels of $\beta$-actin were also detected on these membranes (monoclonal antibody, 1:2,000; Sigma) as a loading control. Bound antibodies were visualized using enhanced chemiluminescence (ECL kit; Amersham Bioscience, UK), exposed to X-ray films, and recorded with a laser scanner. Using Scion image beta 4.0.2 analysis software (Scion Co., Frederick, Md., USA), the mean optical density of c-Met- and NGF-positive protein bands were measured densitometrically and normalized to values for $\beta$-actin.

\section{Statistical Analysis}

All data are presented as means \pm SEM. Paired data were evaluated using Student's t test, and comparisons between multiple groups were performed using one-way analysis of variance (ANOVA) followed by Dunett's tests. $\mathrm{p}$ values $<0.05$ were considered significant.

\section{Results}

\section{c-Met Expression following SNL}

In normal and contralateral L4-L5 DRGs, c-Met was primarily detected in neurons with small to medium diameters and partial 5-HT-positive large-sized neurons (fig. 1A-C). c-Met was not detected in satellite cells (fig. 1D-F), although c-Met and GFAP were found to be co-expressed along the sensory fibers of these DRGs. In the dorsal horn of the corresponding lumbar spinal cords (fig. 2A-C), c-Met immunoreactivity was prominently observed in the superficial laminae occupied by the afferent terminals of DRG sensory neurons, and in association with expression of CGRP, an important neurotrophic and pain-related neuropeptide [27]. In the ventral horns, c-Met immunostaining was mainly observed in the cytoplasm, as well as in proximal dendrites of ChAT-expressing motoneurons (fig. 2D-F).

Following SNL, c-Met immunostaining in ipsilateral versus contralateral L4-L5 DRGs was found to be greatly increased on days 5,7 , and 14 post-ligation (fig. $3 \mathrm{C}, \mathrm{D}, \mathrm{F}$, $\mathrm{H}, \mathrm{J}-\mathrm{L})$, with the highest levels of c-Met expression detected in specimens collected on days 7 and $14(\mathrm{p}<0.05$ in each case; fig. 4A). In the ipsilateral ventral horn of lumbar spinal cords, both immunohistochemistry (fig. 3M-O) and immunoblotting (fig. 4B) for c-Met did not detect changes in c-Met expression over the course of the experimental period. However, c-Met-immunopositive regions within the ipsilateral dorsal horn were found to be significantly enlarged between days 5 and 14, and 
Fig. 2. Immunofluorescent images of cMet in the lumbar spinal cord of a control rat. In the dorsal horn, c-Met co-localized with CGRP (indicated in yellow in $\mathbf{C}$ ) and was confined to laminae I-II (A-C). Most of the motoneurons in the ventral horn were positive for c-Met as indicated by the co-localization of ChAT and c-Met immunoreactivity (D-F). Arrowheads in F indicate the cytoplasmic expression of c-Met and proximal dendrites of spinal motoneurons. Scale bar $=100 \mu \mathrm{m}$ in all panels, with a $50-\mu \mathrm{m}$ scale bar shown in the inset panel of $\mathbf{F}$. IIo = II outer layer, IIi = I inner layer.
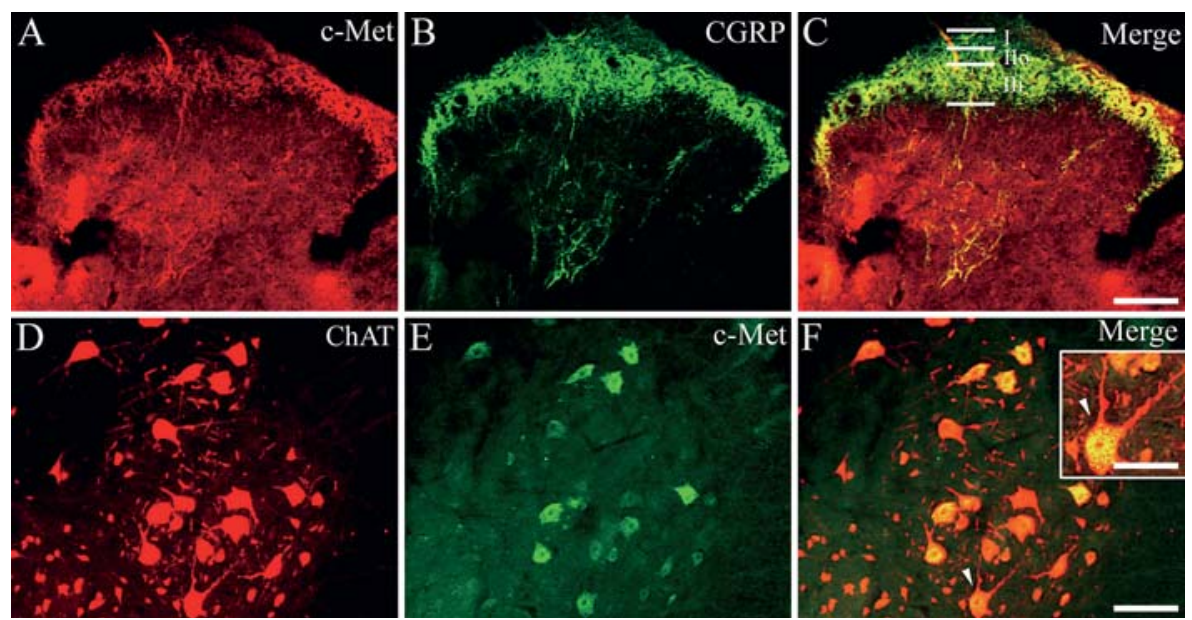

the greatest enlargement was observed on days 7 and 14 post-ligation ( $\mathrm{p}<0.05$ in each case; fig. $4 \mathrm{C}$ ).

\section{HGF Expression following SNL}

In non-injured and contralateral L4-L5 DRGs (fig. 5A), HGF-expressing cells varied widely in size, yet were mainly associated with medium and larger diameter sensory neurons. Following SNL, HGF immunostaining was found to significantly decrease in ipsilateral L4-L5 DRG neurons from day 3 to day 14 , with minimal levels of expression detected on days 5 and 7 ( $p<0.05$ in each case). This decrease in HGF detection was found to gradually increase until day 21 , and was restored to baseline levels by day 28 post-ligation (fig. $5 \mathrm{~B}-\mathrm{H}, \mathrm{J}$ ).

In corresponding lumbar spinal cords, HGF immunoreactivity was detected in superficial laminae of the lumbar spinal dorsal horn, as well as in the cytoplasm and processes of neurons distributed in laminae III-VIII (fig. 5I). Throughout the course of this study, no significant change in expression of HGF across the entire spinal cord was elicited by SNL (data not shown).

\section{Expression of NGF in the Sciatic Nerve following SNL}

Although HGF has been shown to exclusively cooperate with NGF to enhance axonal outgrowth, HGF has also been shown to enhance the neurotrophic activities of NGF. This synergism is specific for NGF and does not occur with other related neurotrophins, such as brain-derived neurotrophic factor and neurotrophin-3 [26]. When axonal transportation in the sciatic nerve was blocked, levels of NGF were found to significantly accumulate as early as $24 \mathrm{~h}$ post-ligation, and this accumulation was found to persist until day 28 in distal nerve segments ( $\mathrm{p}<$ 0.05 vs. proximal segments; see our previous paper [27]).

\section{Discussion}

Using a model of SNL in adult rats, an immediate and persistent accumulation of NGF in the distal sciatic nerve trunk, as well as spatiotemporal changes in the expression of HGF and c-Met, were identified in L4-L5 DRGs and lumbar spinal cords. To the best of our knowledge, these are novel insights into the dynamics of the HGF/cMet signaling system within structures related to peripheral nerve injury signaling.

Previous data have demonstrated that the HGF/c-Met signaling system is necessary for the development, axonal growth, and survival of DRG sensory neurons [26]. In this study, constitutive expression of HGF and c-Met were detected in L4-L5 DRG sensory neurons and in lumbar spinal cords. These results are consistent with previous findings in human and rat models $[9,22,28]$, and are consistent with earlier descriptions of mRNA expression detected using the same animal model [21]. Under physiological situations, spinal motoneurons have been shown to be maintained via $\mathrm{HGF} / \mathrm{c}-\mathrm{Met}$ autocrine and/or paracrine signaling systems [28]. However, in this study, changes in expression of HGF and c-Met following SNL were not detected in spinal motoneurons. These data are consistent with previous reports of SNL where levels of HGF mRNA were unaffected [21]. Furthermore, in studies of sciatic nerve transaction, HGF protein levels were found to be unaffected in lumbar spinal cords [25], suggesting that the regulation of the HGF/c-Met system in central motoneurons following peripheral nerve injury differs from that following central nerve injury, which has been associated with up-regulation of both HGF and c-Met [9].

In adult rats, a significant increase in c-Met mRNA has been detected in Schwann cells of the distal nerve seg- 

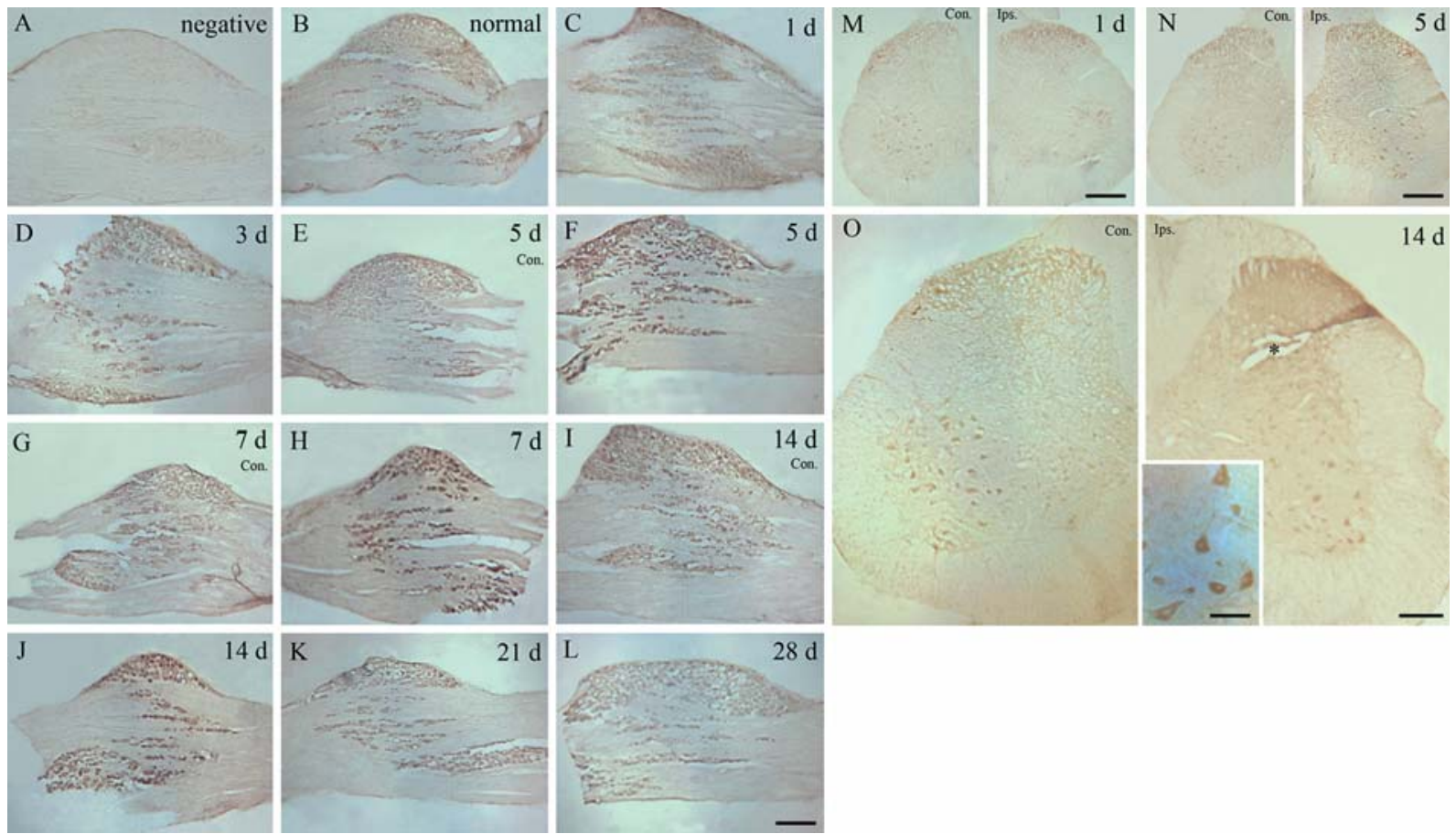

Fig. 3. Representative microphotographs of c-Met immunoreactivity in L4-L5 DRGs and lumbar spinal cords following SNL. cMet immunoreactivity in L4-L5 DRGs (A-L), and an area in the dorsal horn, increased on day 5 through day 14 following injury $(\mathbf{N}, \mathbf{O})$. In contrast, c-Met immunostaining in ventral motoneu- rons remained unchanged (M-O). An asterisk marks the ipsilateral side. The inset panel in $\mathbf{O}$ showing the higher magnification profile of spinal motoneurons came from the same ipsilateral ventral horn. Scale bars $=250 \mu \mathrm{m}$ in $\mathbf{A}-\mathbf{L}$, and $100 \mu \mathrm{m}$ in the inset panel of $\mathbf{O}$. Con. $=$ Contralateral side, Ips. $=$ ipsilateral side. ment as early as day 4 following SNL, whereas up-regulation of c-Met mRNA in proximal nerve segments of Schwann cells was not detected until day 14 following SNL [21]. This unique induction pattern for c-Met mRNA post-injury suggests that the HGF/c-Met system may have a functional role in promoting axon regeneration based on the concentration and frequency of interactions between c-Met and HGF on the surface of injured Schwann cells. In the present study, a significant decrease in HGF expression was coupled with a significant increase in c-Met levels in L4-L5 DRG neurons and their afferent terminals following SNL. These findings suggest that the HGF/c-Met system in DRG primary sensory neurons is sensitive to peripheral nerve injury signaling, and in contrast with motoneurons, L4-L5 DRG sensory neurons could be protected from nerve injury signaling by increased expression of c-Met.

Both in vitro and in vivo, HGF has been shown to be a strong neurotrophic factor for motoneurons $[5,28,29]$. For example, after facial nerve or seventh cervical segment (C7) nerve avulsion, adenoviral gene transfer of HGF was shown to prevent significant loss, as well as ameliorate ChAT immunoreactivity in injured motoneurons of adult rats [23]. Similarly, continuous administration of HGF to the severed ends of hypoglossal nerves markedly prevented a reduction in protein and mRNA levels of ChAT, and significantly decreased the transcription and translation of c-Met in adult rats. In the latter situation, levels of c-Met gradually increased and reached maximal levels 2 weeks following axotomy [24]. Recent evidence has also confirmed that repeated transfer of the human HGF gene into the rat nervous system can promote the functional recovery and repair of injured nerves $[8,30]$. In the spinal cord, high expression levels of the cMet receptor have been found to be restricted to subsets of motoneurons, particularly those associated with limbinnervating segments $[31,32]$. However, in this study, protein levels of HGF/c-Met did not indicate that motoneurons of the lumbar spinal cord had been affected following SNL. Therefore, in combination with previous findings $[21,25]$, we hypothesize that the HGF/c-Met system may exert protective effects on injured spinal motoneurons through increases in activity, rather than changes in protein expression, following peripheral nerve in- 


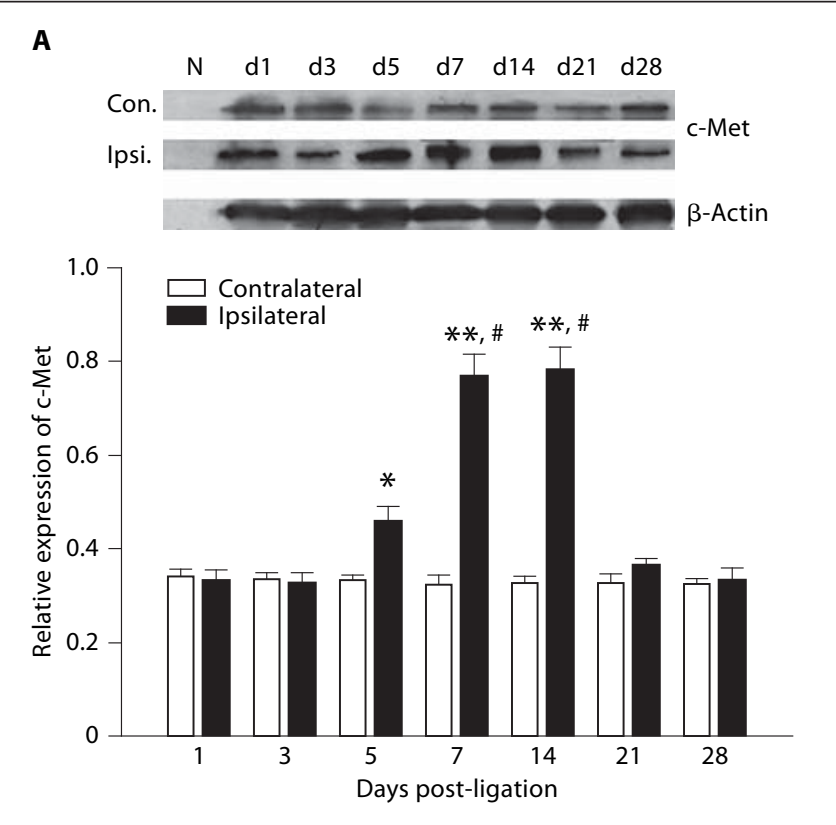

Fig. 4. Immunoblotting and quantitative analysis of c-Met expression. Total protein lysates from L4-L5 DRGs (A) and spinal motoneurons (B) were analyzed by Western blot for c-Met expression. $\beta$-Actin was used as a loading control and for normalization of c-Met expression values quantitated by densitometry. The area of c-Met expression in the dorsal horn (C) following SNL was also quantified. The values presented are the means \pm SEM, with $n=$ 5. Significant differences were detected between the contralateral and ipsilateral sides $(\mathbf{A}, \mathbf{C})\left({ }^{*} \mathrm{p}<0.05\right.$ and $\left.{ }^{* *} \mathrm{p}<0.01\right)$, as well as for other examined timepoints between the ipsilateral sides $\left({ }^{\#} \mathrm{p}<\right.$ 0.05). $\mathrm{N}$ in $\mathbf{A}=$ negative control. Con. = Contralateral side, Ipsi. $=$ ipsilateral side

jury. Since HGF is a physiologically relevant survival factor for a subpopulation of developing spinal motoneurons [31], the unchangeableness of HGF/c-Met signaling observed in this study also represents the vulnerable difference to injury signaling that exists between the immature central motoneurons and the mature ones.

HGF cooperates with CNTF to promote the survival of motoneurons and parasympathetic neurons [33, 34]. Moreover, HGF in combination with NGF is able to promote the survival of sensory neurons and outgrowths of sensory and sympathetic axons $[26,35,36]$. Although cMet expression in the sciatic nerve was not assayed, NGF was observed to dramatically accumulate in the distal segment of the sciatic nerve as early as $24 \mathrm{~h}$ post-ligation [27]. This accumulation of NGF persisted for the duration of the experiment. Based on the increase in neurotrophic ef-
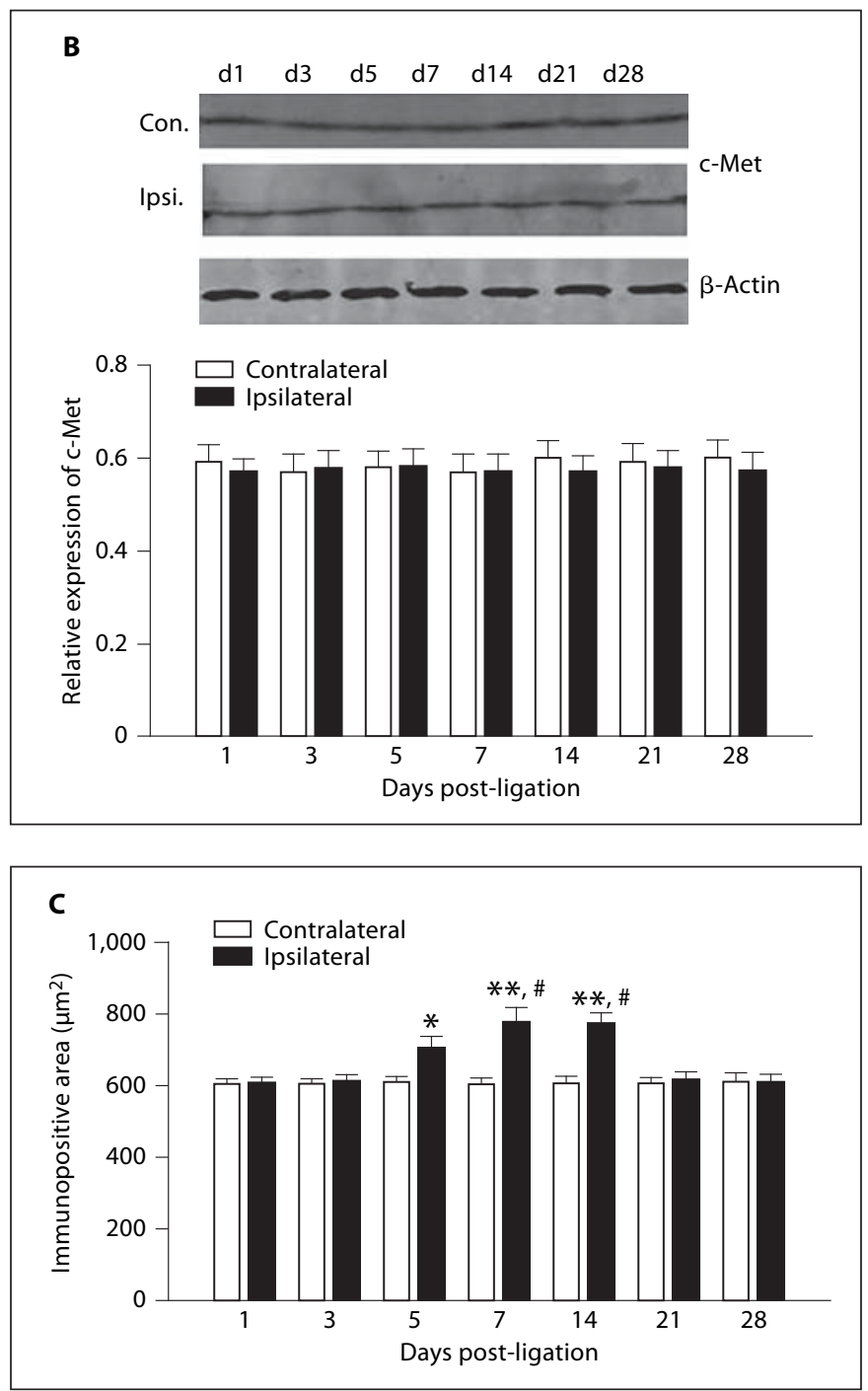

fects mediated by HGF in the presence of NGF $[26,35]$, the immediate accumulation of NGF following peripheral axon injury in distal sciatic nerve segments predicts its involvement in the promotion of axon regeneration by $\mathrm{HGF} / \mathrm{c}-\mathrm{Met}$ signaling. However, the exact mechanism(s) and function(s) mediated by NGF remain to be elucidated.

Sun et al. [37] found that the expression of c-Met and HGF RNAs in spinal motoneurons revealed increased expression levels during progression of amyotrophic lateral sclerosis in G93A mice. Consistently, throughout the course of this disease, certain residual spinal motoneurons co-expressed both HGF and c-Met proteins with the same, or even stronger intensity in comparison with those of normal subjects in human histological studies [28], suggesting that the new protein synthesis of the HGF/c-Met system could be a factor in charge of the degeneration of 

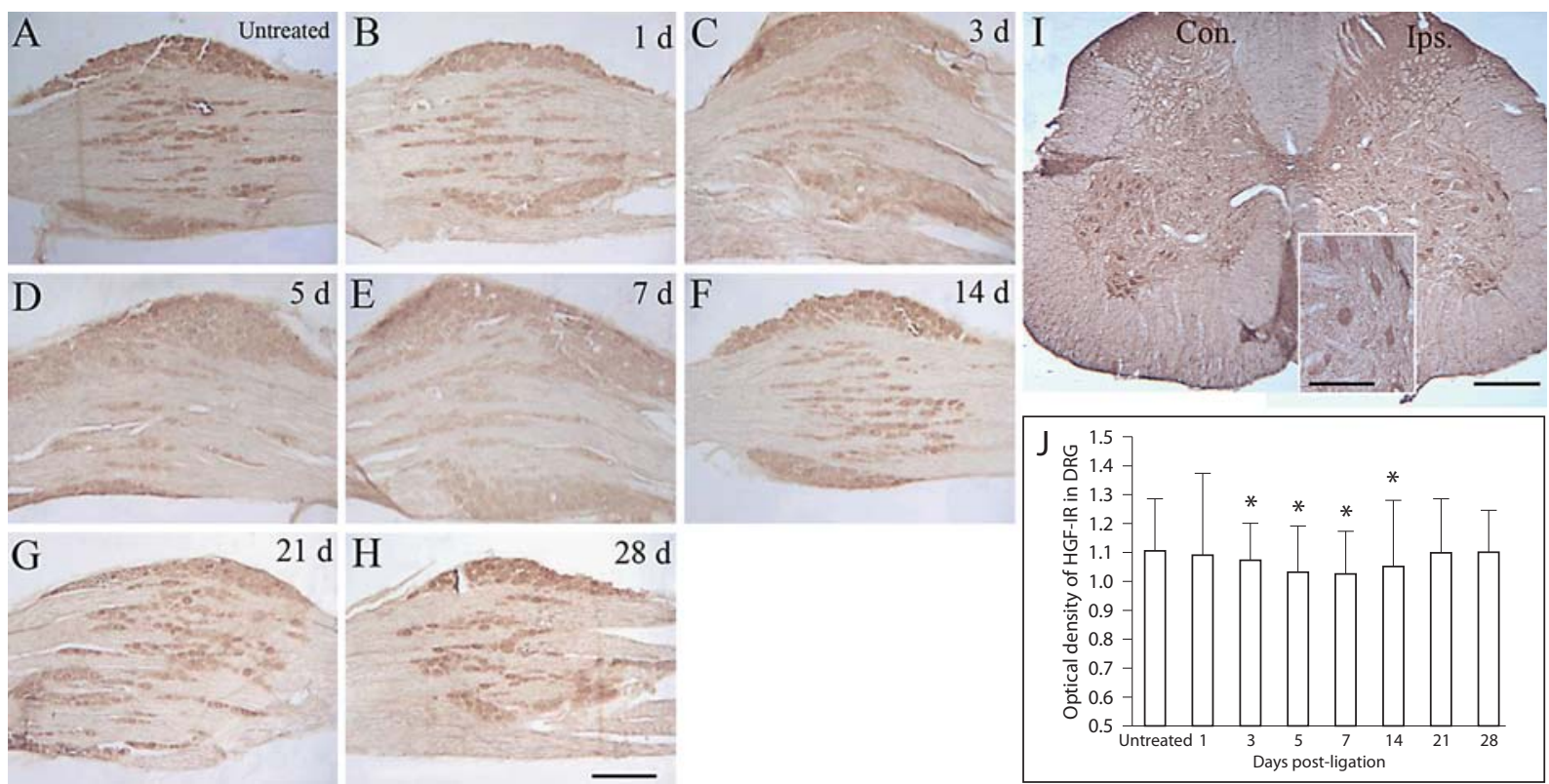

Fig. 5. Representative microphotographs of HGF immunohistochemistry in L4-L5 DRGs and lumbar spinal cords following SNL. HGF immunoreactivity in L4-L5 DRGs (A-H) decreased between days 3 and 14, whereas HGF expression in ventral moto-

these injured neurons. However, in the PNS, SNL injury did not alter the expression of the HGF/c-Met system [21]. Besides the NGF accumulation in the nerve trunk as early as 1 day post-injury, in this study, it was spatiotemporally revealed that the HGF protein level was significantly down-regulated in DRG sensory neurons from day 3 to day 14 and followed by c-Met up-regulation in these neurons and their afferents from day 5 to day 21 following ligation. Usually, dynamic regulation of $\mathrm{HGF} / \mathrm{c}-\mathrm{Met}$ signaling implicates its multiple roles in the development, maintenance and modification of the nervous system [38]. This spatiotemporal patter but not the consistent increase in the involved regions implies that $\mathrm{HGF} / \mathrm{c}-$ Met system possibly protects the injured neurons from assault damage via its dynamic regulation rather than new protein synthesis.

In summary, spatiotemporal regulation of $\mathrm{HGF} / \mathrm{c}-\mathrm{Met}$ expression in DRG sensory neurons and spinal motoneurons of adult rats in response to peripheral nerve injury has been demonstrated. Expression of HGF/c-Met, as well as levels of NGF levels in the nerve trunk, showed unique regulatory patterns, indicating that the HGF/c-Met system is dynamically regulated in response to peripheral nerve injury. In addition, the $\mathrm{HGF} / \mathrm{c}-\mathrm{Met}$ system was shown to promote the survival of injured neurons, especially DRG sensory neurons in the adult rat.

neurons remained unchanged (I). Densitometric quantitation of HGF staining in L4-L5 DRGs is shown $(\boldsymbol{J}) .{ }^{*} \mathrm{p}<0.05$, compared to the normal group. Scale bars $=250 \mu \mathrm{m}$ in $\mathbf{A}-\mathbf{I}$, and $100 \mu \mathrm{m}$ in the inset panel of $\mathbf{I}$.

\section{Acknowledgements}

This work was supported by grants from the National Natural Science Foundation of China (Nos. 30760259, 30860290 and 30901730), the Doctoral Innovation Fund of Shanghai Jiaotong University School of Medicine (BXJ201043) and the Nano Specialized Research Fund of Shanghai Science and Technology Commission (No. 1052nm05800).

References hara A: L-Proline is an essential amino acid for hepatocyte growth in culture. Biochem Biophys Res Commun 1984;122:884-891.

-2 Nakamura T, Nishizawa T, Hagiya M, Seki T, Shimonishi M, Sugimura A, Tashiro K, Shimizu S: Molecular cloning and expression of human hepatocyte growth factor. Nature 1989;342:440-443.

- 3 Hamanoue M, Takemoto N, Matsumoto K, Nakamura T, Nakajima K, Kohsaka S: Neurotrophic effect of hepatocyte growth factor on central nervous system neurons in vitro. J Neurosci Res 1996;43:554-564.

4 Maina F, Klein R: Hepatocyte growth factor, a versatile signal for developing neurons. Nat Neurosci 1999;2:213-217. 
$\checkmark 5$ Caton A, Hacker A, Naeem A, Livet J, Maina F, Bladt F, Klein R, Birchmeier C, Guthrie S: The branchial arches and HGF are growthpromoting and chemoattractant for cranial motor axons. Development 2000;127:17511766.

-6 Ebens A, Brose K, Leonardo ED, Hanson MG, Bladt F, Birchmeier C, Barres BA, Tessier-Lavigne M: Hepatocyte growth factor scatter factor is an axonal chemoattractant and a neurotrophic factor for spinal motor neurons. Neuron 1996;17:1157-1172.

7 Funakoshi H, Nakamura T: Identification of HGF-like protein as a novel neurotrophic factor for avian dorsal root ganglion sensory neurons. Biochem Biophys Res Commun 2001;283:606-612.

8 Kato N, Nemoto K, Nakanishi K, Morishita R, Kaneda Y, Uenoyama M, Ikeda T, Fujikawa $\mathrm{K}$ : Nonviral HVJ (hemagglutinating virus of Japan) liposome-mediated retrograde gene transfer of human hepatocyte growth factor into rat nervous system promotes functional and histological recovery of the crushed nerve. Neurosci Res 2005;52:299-310.

-9 Kitamura K, Iwanami A, Nakamura M, Yamane J, Watanabe K, Suzuki Y, Miyazawa D, Shibata S, Funakoshi H, Miyatake S, Coffin RS, Nakamura T, Toyama Y, Kano H: Hepatocyte growth factor promotes endogenous repair and functional recovery after spinal cord injury. J Neurosci Res 2007;85:23322342.

-10 Miyazawa T, Matsumoto K, Ohmichi H, Katoh H, Yamashima T, Nakamura T: Protection of hippocampal neurons from ischemia-induced delayed neuronal death by hepatocyte growth factor: a novel neurotrophic factor. J Cerebr Blood Flow Metab 1998;18: 345-348.

-11 Niimura M, Takagi N, Takagi K, Funakoshi H, Nakamura T, Takeo S: Effects of hepatocyte growth factor on phosphorylation of extracellular signal-regulated kinase and hippocampal cell death in rats with transient forebrain ischemia. Eur J Pharmacol 2006; 535:114-124.

12 Ishigaki A, Aoki M, Nagai M, Warita H, Kato S, Kato M, Nakamura T, Funakoshi H, Itoyama Y: Intrathecal delivery of hepatocyte growth factor from amyotrophic lateral sclerosis onset suppresses disease progression in rat amyotrophic lateral sclerosis model. J Neuropathol Exp Neurol 2007;66:10371044.

13 Koike H, Ishida A, Shimamura M, Mizuno S, Nakamura T, Ogihara T, Kaneda Y, Morishita R: Prevention of onset of Parkinson's disease by in vivo gene transfer of human hepatocyte growth factor in rodent model: a model of gene therapy for Parkinson's disease. Gene Ther 2006;13:1639-1644.

-14 Date I, Takagi N, Takagi K, Kago T, Matsumoto K, Nakamura T, Takeo S: Hepatocyte growth factor improved learning and memory dysfunction of microsphere-embolized rats. J Neurosci Res 2004;78:442-453.
15 Bottaro DP, Rubin JS, Faletto DL, Chan AM, Kmiecik TE, Vande Woude GF, Aaronson SA: Identification of the hepatocyte growth factor receptor as the c-Met proto-oncogene product. Science 1991;251:802-804.

16 Jung W, Castren E, Odenthal M, Vande Woude GF, Ishii T, Dienes HP, Lindholm D, Schirmacher P: Expression and functional interaction of hepatocyte growth factorscatter factor and its receptor c-Met in mammalian brain. J Cell Biol 1994;126:485-494.

-17 Sun W, Funakoshi H, Nakamura T: Localization and functional role of hepatocyte growth factor and its receptor c-Met in the rat developing cerebral cortex. Mol Brain Res 2002;103:36-48

-18 Shibuki H, Katai N, Kuroiwa S, Kurokawa T, Arai J, Matsumoto K, Nakamura T, Yoshimura N: Expression and neuroprotective effect of hepatocyte growth factor in retinal ischemia-reperfusion injury. Invest Ophthalmol Vis Sci 2002;43:528-536.

19 Thewke DP, Seeds NW: The expression of MRNAS for hepatocyte growth factor/scatter factor, its receptor c-Met, and one of its activators tissue-type plasminogen activator show a systematic relationship in the developing and adult cerebral cortex and hippocampus. Brain Res 1999;821:356-367.

20 Achim CL, Katyal S, Wiley CA, Shiratori M, Wang G, Oshika E, Petersen BE, Li JM, Michalopoulos GK: Expression of HGF and CMET in the developing and adult brain. Dev Brain Res 1997;102:299-303.

21 Hashimoto N, Yamanaka H, Fukuoka T, Dai Y, Obata K, Mashimo T, Noguchi K: Expression of HGF and CMET in the peripheral nervous system of adult rats following sciatic nerve injury. Neuroreport 2001;12:14031407.

22 Hashimoto N, Yamanaka H, Fukuoka T, Obata K, Mashimo T, Noguchi K: Expression of hepatocyte growth factor in primary sensory neurons of adult rats. Brain Res Mol Brain Res 2001;97:83-88.

-23 Hayashi Y, Kawazoe Y, Sakamoto T, Ojima M, Wang W, Takazawa T, Miyazawa D, Ohya W, Funakoshi H, Nakamura T, Watabe K: Adenoviral gene transfer of hepatocyte growth factor prevents death of injured adult motoneurons after peripheral nerve avulsion. Brain Res 2006;1111:187-195.

24 Okura Y, Arimoto H, Tanuma N, Matsumoto K, Nakamura T, Yamashima T, Miyazawa T, Matsumoto Y: Analysis of neurotrophic effects of hepatocyte growth factor in the adult hypoglossal nerve axotomy model. Eur J Neurosci 1999;11:4139-4144.

25 Pan F, Chen AM, Guo FJ, Zhu CL, Tao FH: Effect of FK-506 on expression of hepatocyte growth factor in murine spinal cord following peripheral nerve injury. J Huazhong Univ Sci Technol Med Sci 2008;28:159-162.

-26 Maina F, Hilton MC, Ponzetto C, Davies AM, Klein R: Met receptor signaling is required for sensory nerve development and HGF promotes axonal growth and survival of sensory neurons. Gene Dev 1997;11:33413350.

27 Zheng LF, Wang R, Xu YZ, Yi XN, Zhang JW, Zeng ZC: Calcitonin gene-related peptide dynamics in rat dorsal root ganglia and spinal cord following different sciatic nerve injuries. Brain Res 2008;1187:20-32.

$\checkmark 28$ Kato S, Funakoshi H, Nakamura T, Kato M, Nakano I, Hirano A, Ohama E: Expression of hepatocyte growth factor and c-Met in the anterior horn cells of the spinal cord in the patients with amyotrophic lateral sclerosis (ALS): immunohistochemical studies on sporadic ALS and familial ALS with superoxide dismutase 1 gene mutation. Acta Neuropathol 2003;106:112-120.

-29 Koyama J, Yokouchi K, Fukushima N, Kawagishi K, Higashiyama F, Moriizumi T: Neurotrophic effect of hepatocyte growth factor on neonatal facial motor neurons. Neurol Res 2003;25:701-707.

>30 Li Z, Peng J, Wang GJ, Yang Q, Yu HL, Guo QY, Wang AY, Zhao B, Lu SB: Effects of local release of hepatocyte growth factor on peripheral nerve regeneration in acellular nerve grafts. Exp Neurol 2008;214:47-54.

-31 Yamamoto Y, Livet J, Pollock RA, Garces A, Arce V, deLapeyriere O, Henderson CE: Hepatocyte growth factor (HGF/SF) is a muscle-derived survival factor for a subpopulation of embryonic motoneurons. Development 1997;124:2903-2913.

-32 Shimamura M, Sato N, Sata M, Wakayama K, Ogihara T, Morishita R: Expression of hepatocyte growth factor and c-Met after spinal cord injury in rats. Brain Res 2007;1151: 188-194.

33 Davey F, Hilton M, Davies AM: Cooperation between HGF and CNTF in promoting the survival and growth of sensory and parasympathetic neurons. Mol Cell Neurosci 2000;15:79-87.

34 Wong V, Glass DJ, Arriaga R, Yancopoulos GD, Lindsay RM, Conn G: Hepatocyte growth factor promotes motor neuron survival and synergizes with ciliary neurotrophic factor. J Biol Chem 1997;272:51875191.

35 Maina F, Hilton MC, Andres R, Wyatt S, Klein R, Davies AM: Multiple roles for hepatocyte growth factor in sympathetic neuron development. Neuron 1998;20:835-846.

36 Yang XM, Toma JG, Bamji SX, Belliveau DJ, Kohn J, Park M, Miller FD: Autocrine hepatocyte growth factor provides a local mechanism for promoting axonal growth. J Neurosci 1998;18:8369-8381.

-37 Sun W, Funakoshi H, Nakamura T: Overexpression of HGF retards disease progression and prolongs life span in a transgenic mouse model of ALS. J Neurosci 2002;22:65376548.

38 Sun W, Funakoshi H, Nakamura T: Differential expression of hepatocyte growth factor and its receptor, c-Met in the rat retina during development. Brain Res 1999;851: 46-53. 